\title{
X-ray Cargo Scanning and Risk Management in Trade Facilitation: Analysis \& Model of an Online Imaging and Documentation Management System
}

\author{
Wilson Nwankwo \\ Department of Computer Science, Edo University Iyamho, Edo State, Nigeria \\ Email: nwankwo.wilson@edouniversity.edu.ng \\ Akinola S. Olayinka \\ Department of Physics, Edo University Iyamho, Edo State, Nigeria \\ Email: akinola.olayinka@edouniversity.edu.ng; \\ Benjamin Uchenna Benson \\ Department of Computer Science, Imo State University of Agric. \& Env. Sciences, Umuagwo, Nigeria \\ Email: gentlebenblack@gmail.com
}

Received: 12 April 2019; Accepted: 28 April 2019; Published: 08 May 2019

\begin{abstract}
In the last two decades many document management systems have evolved and have been deployed for use in business areas such as marketing, production, sales, shipping, banking, education, etc. The demand for electronic document management system has continued to rise with new application areas discovered from day to day. This paper is the first of a two-part study that dwells on the conceptualization, development and deployment of an online documentation system for trade facilitation applications. This paper demonstrates how an organization can build a cost-effective and efficient electronic document management system using open source like MySQL and PHP. The domain of application stressed in this paper is X-ray Cargo Scanning operations as conducted by Government agencies especially the Customs and Excise or their appointees during imports, exports inspection and cargo clearance at the ports. In this paper, the authors investigated various operations that preceed clearance of shipments at ports in Lagos Nigeria. The role of Cargo scanners, image acquisition and subsequent analysis as well as challenges were buttressed. Following the investigation, analysis and design of a solution were done. This paper presents the results of the analysis as well as the system specifications which are considered vital for the implementation of a realtime integrated solution. The proposed system would provide a platform that enhances productivity in a risk management and scanning service organization especially in managing and exchanging large volumes of scanner-generated documentation across a network as well as with other agencies.
\end{abstract}

Index Terms-Risk Management, Trade Facilitation, Imaging, X-ray Cargo Scanners, Documentation System, Imports

\section{INTRODUCTION}

Realtime Electronic Document Management Systems promise great returns on investment for many organizations that are data-driven $[1,2]$. Document management pervades all public sector and private sector operations. Banks, Construction, Manufacturing, Justice Administration, Transport and Logistics, Insurance, etc. utilize various documents in their day to day transactions. Government agencies and ministries are not left out as they rely on information provided in different documents to operate. Automation has become the cornerstone of strategic planning in the modernization programmes of most organizations in order to remain competitive and operationally efficient $[3,4,5,6]$. These automated solutions perform vital roles in supporting information exchange processes across levels of management, operations, as well as stakeholders on the one hand and increase the efficiency,viability, visibility and competitive advantage of the organization on the other hand[7,8,9,10,11,12].

In the International trade sector, efficiency may be attained through marked reduction in processing time especially for imported goods for resale which is often affected by time. Risk management is a vital component of international trade facilitation and often requires a structurally effective workflow. The foregoing is due to the fact that Risk Management organizations may be required by government policy on imports to conduct huge inspection operations on containerized and non containerized imports. Such operations are not only directed to boost revenue generation but to reduce hazards that may occur during physical inspections, as well as ebsure national security. A modern way of managing risk-intensive shipments at destination ports is through 
high capacity X-ray scanning, a non-intrusive and effective way of conducting inspection. The results of such scanning operations are to be stored, analyzed and relayed via a communication network for decision making. In addition, most vital transactions between such organizations, commercial banks and other government agencies are often executed via documents and this makes such organizations highly document-oriented enterprises.

To operate efficiently in high traffic ports like Apapa ports in Lagos Nigeria, a seamless integration of an electronic document management system in the information technology (IT) cannot be overemphasized. In this paper a novel approach is proposed whereby $\mathrm{x}$-ray scanning operations at different operational ports could be managed through a centralized system. The digitized files can be stored as base 64 strings in the database and reconverted when needed. The storage of these large image files as base 64 strings in the database would ease information exchange via an Electronic Data Interchange (EDI) using simple extensible markup language (XML).

\section{A. Overview of Scanning and Risk Management} operations

Cargo Scanning is a risk management procedure aimed at eliminating human interventions in the inspection of shipments. The process involves the use of Scanners for high resolution X-ray inspection of imported goods conveyed through containers and trucks. The essence of the process is to capture high resolution images of concealed and non-concealed products as well as enabling the subjection of such images to routine digital image analysis using sophisticated image analysis software.

\section{$X$-ray Cargo scanners}

$\mathrm{X}$-ray technology is central to the scanner function. Prior to deployment of these high emission devices in any site in Nigeria, the National Nuclear Regulatory Authority (NNRA) usually conducts a safety and operational assessment which if satisfactory would issue a certificate, a sort of license that permits owners to operate within the tenets of the license. Non-intrusive inspection using scanners is vital to the detection of explosives, weapons, narcotics and contraband such as cigarettes and alcohol in baggage, trucks and freight. These scanners come in various capacities and sizes. There are three common categories of scanners that are deployed at the ports namely: the mobile scanners [13], the fixed scanners [14, $15]$ and gantry scanners [15].

The Mobile Scanners are in the form of a 'drivable' large vehicle that can be driven from site to site. A typical example is the Smiths $H C V C A B 2000 M$ which is designed for the detection of illegal consignments inside trucks and sealed containers. Powerful penetration combined with low radiation dosage make scanners in the category of HCV CAB $2000 \mathrm{M}$ an excellent mobile X-ray tool. The system has two parts: the operation module, based on a $20 \mathrm{ft}$. container platform, and the transport module, which is a standard road transport vehicle equipped with a swap body platform (Class C 745, EN 284). The system configuration allows a fast inspection procedure of the cargo without the need to open the container or truck. The mobile concept of the system allows the integration into nearly every existing inspection infrastructure. System setup as well as dismantling may take less than one hour.

The Fixed scanners on the other hand are built and assembled at a specific location and cannot be moved. An example is the Smiths Detection's HI-SCAN 180180-2is pro [16] which is specially designed to meet the needs and applications of airports, sea ports, transportation operations, carriers, etc. It is a compact medium energy (300 kV) X-ray cargo inspection system with tunnel dimensions of at least $1800 \mathrm{~mm}$ (71") wide and $1800 \mathrm{~mm}$ (71") high. It permits the inspection of pallets and LD-3 airfreight containers. The HI-SCAN 180180-2 is equipped with two generators thus beaming in two directions (Dual View). This particular screening mode facilitates reliable inspections in one process while shortening inspection times and increasing the effectiveness of the procedure. [16]

\section{Network infrastructure}

The Network Infrastructure provides a communication platform between the scanner, workstations and remote devices. Through the network infrastructure, which is seldom a fibre optics medium large volume of documents and captured images are exchanged.

\section{Storage devices}

A number of storage devices are needed in cargo scanning sites due to the high volume of data generated. Common storage devices include; digital video discs (DVDs), external hard disks, and arrays.

\section{Imaging and image analysis software system}

An Image analysis system is a major subsystem of the scanning procedure [17]. This system is run from a computer-like workstation within the scanner. The system provides different techniques and options to the users for dealing with captured images. The scanning report is to a great extent influenced by the sophistication of this software as well as the specialist image analysts. The scanning report is the end result of the scanning process and includes all findings from the image analysis activity. This sensitive document is accompanied with all the processed images of the shipment (with the areas of concern vividly highlighted).

\section{B. Statement of the Problem}

In the process of trade facilitation, a large volume of import related documentation such as single goods declaration(SGD), bill of lading(BOL), airway bill(AWB), road way bill(RWB), proforma invoice, combined certificate of value and origin(CCVO), packing list, import manifest, Form M(applicable to Nigeria), etc. are often generated. These documents are vital for decision-making and future undertakings hence should be appropriately managed. As a case study, most risk management and scanning service organizations in Nigeria are disposed to three categories of documents: 
internally generated, external documents (documents received from Commercial Banks, Central Bank of Nigeria (CBN), Ministry of Finance, etc), and legacy documents. Often times the following problems are common in these organizations:

\section{i. Poorly structured document life cycle \\ ii. Existence of a highly compacted document storage room that promotes file losses. \\ iii. Absence of rules and regulatory measures on document creation, manipulation, use and storage, which invariably subject critical documents to abuses. \\ iv. Scanned results stored on compact disks and DVDs often get corrupted making future referencing impossible. \\ v. Transfer and management of scanned images and multimedia documents to DVDs consumes much resources and time.}

\section{Importance of the Study}

This study is relevant in that it tried to:

a. Discuss the structure of operations and procedures in an ideal risk management and scanning services organizations (RMSSO).

b. Collect and analyse data on information flow, utilization and management as well as the available channels used in managing information in a Risk Management and Scanning Service Organization.

c. Provide details as to how electronic document management systems would serve as important infrastructure in International trade facilitation especially as relevant to activities of Risk Management and Scanning Service Organizations.

d. Explain how the efficiency in operations of such organizations could be reasonably improved through the deployment of specialized Electronic Document Management Systems.

\section{Research Questions}

This paper is designed to seek answers to the following questions:

i. How does the creation, workflow, organization, retrieval, transmission and storage of documents and data affect the efficiency and effectiveness of Risk Management and Scanning Service operations?

ii. Whether or not there is an improved system for conducting the tasks stated in (i) above.

iii. What are the basic requirements for implementing an improved electronic document management system?

iv. What tasks should be undertaken by an electronic documentation system tailored to the needs of a Risk Management and Scanning Service Organization? v. Are there significant benefits that would be derived from the proposed system?

vi. What are the limitations to the adoption of such a system in a Risk Management and Scanning Service Organization?

\section{RELATED WORK}

\section{A. Document Modeling in Automation}

Most document models comes in the form of document templates evidenced most often as word-processing documents, portable document format(PDF) forms, XML templates. XML is peculiar due to its flexibility and ability to represent documents in a tree-like structure, as well as its separation of content and style. Document modeling goes beyond form-filling and mail-merge and considers the structure of data in, for example, a legal document, a contract, an inspection report, bank account report, etc. The results of a sophisticated document model may surpass those of any specialist in terms of flexibility and cost-effectiveness.

\section{B. Document Management Systems (DMS)}

DMS well-documented and defined as a system for managing collection of documents. A DMS is the sum total of all organizational processes from the creation to the storage/archival, security, retrieval and eventually to the destruction of documents.

The EDMS as a specie of DMS, stores electronic versions of all documents, usually but not restricted to scanned copies of paper documents and electronically generated documents $[18,19,20,21,22,23]$. A good electronic document management system is one of the best ways to streamline business processes and increase productivity.

\section{Document Management and Communication}

According to Carzaniga and Wolf [24] "electronic document is a major component of content-based networking communication infrastructure where information is driven by the content throughout the network". The users express their interests, and the senders simply input the message into the network. From that point the network delivers all the information to the right people.

Haas \& Hansen [25] elaborated on the role of the suppliers and users of information in electronic documents.

Marin \& Poulter [26] posit that if all data and information would be put in a central database or over an intranet, to be used by everyone in an organization, there would be a clear link between Iiformation Technology and dissemination of information. They argue that due to the ease of access to information there would be a smooth flow of communication through the organization. Accordingly, distribution of intelligence can be aided by technology. 


\section{Approaches to Document Management Systems}

\section{The Native approach}

The traditional approach of DMSs is based on the client/server architecture. Typically, the DMS runs on the enterprise server system, while every client runs proprietary software, which provides user interface and access to documents. The link between clients and the server is via a local area network. This approach requires expensive client software for every desktop.

\section{Web-based/Internet-based approach}

The web-based approach in DMS deployment is based on the three-tier architecture. The system consists of clients (tier 1), the document server (tier 2) and databases (tier 3). Clients are connected to the server through the Intranet or the Internet. The document server implements the document repository and the document management software.

The DMS software is used for workflow, process automation services, controlling and managing documents, and other processes throughout distributed enterprises. The document client software typically includes desktop and Intranet (or Internet) clients, which enable users to access and view documents stored in one or more document repositories from their desktops or Web browsers. These systems are not usually built as XML document managers; however some of the vendors allow that they can be configured to work with XML documents. In modern web-based document management systems, most attributes of the documents are stored on a structured or object-oriented database system.

\section{Integrated Document approach}

The integrated approach documents are like black-boxes. The goal is to afford an easy information retrieval using reference information. It is adjudged as one of the best approaches to EDMS design [27, 28, 29].

\section{Model-based approach}

The model-based approach consolidates all data in a single integrated database from which information can be fetched using queries, and written documents can be produced almost automatically[30,31,32].

A variation of this approach is the application service provider (ASP) model whereby the application engine and modules are provided by a third party over a network particularly the Internet. Users can log onto the application via the web browser, use the provider's application to perform all the document management operations and can even store documents and data on the provider's repository.

\section{Enterprise Document Management systems (EnDMS)}

The EnDMS is a strategy directed at managing an organization's paper and electronic documents in such a way that they can easily be retrieved in the event of a compliance audit or subpoena. The term originally referred to electronic documents that were created on a computer or paper documents that were scanned into a digital format. In recent times the EnDMS nclude email, faxes, instant messages, PowerPoint presentations, collaborative software entries and multimedia. It may be used to create a single view of all an enterprise's information repository and provide workflow tools to monitor and control modifications.

From improved handling of documents to providing a structured storage, an EDMS removes the entire burden associated with storing paper records.

\section{E. Classification of EDMS}

EDMS may categorized based on various criteria such as: architecture, and application. Architecturally, an EDMS may be a desktop/standalone systems, client-server systems, Web EDMS or a multi-tier EDMS; whereas by application, the areas of EDMS use is emphasized e.g. Justice administration and law practice, financial, medical, health, land and estate management, engineering, e-government, educational administration, manufacturing and production,etc.

\section{F. Document Management Standards}

Software systems are currently indispensable in day to day business and non business activities. Basically, two standards are recognized: open, and closed standards. Open standards include among others; Open Document Management Application Program Interface [33], Document Management Alliance [34], ISO/TC171[35], Web-based Distributed Authoring and Versioning (WebDAV)/DeltaV [36]. An advantage using open source tools is that they often have a large community which develop/adapt the tool over time. Even if the software support is discontinued developers can adapt the software because they have access to the source code.

\section{G. Motivation for the Study}

EDMS is an integral part of a larger IT infrastructure and in a risk management environment involving the storage and movement of x-ray scanner-acquired images in a specific format, not any EDMS is appropriate considering integration constraints. This paper provides a succinct analysis model following the investigation of a cargo scanning workflow, transmission and processing of multimedia documentation in a scanning and risk services facility. The objects of concern include access time, reliability, accessibility and cost-effectiveness. The specific objective is to identify the document management and workflow needs of such organizations; and produce an implementable model of a cost-effective system for managing workflow associated with scanning operations using one or a mix of any of the approaches discussed above. 


\section{MATERIAL AND METHOD}

\section{A. Materials}

The materials employed during the design are:
i. A $2.5 \mathrm{GHz}$ Core-i5 PC with 8GB RAM and 750GB hard disk
ii. Microsoft Windows 8.1 Operating system
iii. Erwin Data Modeler Software
iv. Microsoft Visual Studio 2015 Software
V. Paper questionnaires

\section{B. Method}

Systematic observation: the researchers observed all operations in real time at selected cargo scanning sites in Lagos Nigeria and recorded all observations made.

Unstructured interview: Some operational personnel (site supervisor, image analysts, documentation specialists and technical officers) were surveyed on the efficiency of the existing system of documenting and transmitting electronic documents. Their opinions regarding how the system could be improved were sought and their reactions recorded.

The details of the method are discussed in succeeding sections.

\section{Research Design}

The design of this study follows a hybrid one i.e. a mix of qualitative and system approaches. The qualitative component was necessary in data collection and summarization whereas the system approach involved the use of structured system analysis and design method (SSADM). SSADM offers the following benefits: Clear requirements statement that everyone can understand and form a firm foundation for subsequent design and implementation; Improved project planning and control; Usability; Respond to changes in the business environment; Effective use of skills; Better quality; Improvement of productivity: Cuts costs. The process of data collection involved some field investigation on the existing system.

\section{Population}

The study population was selected using quota sampling. The population comprises ninety-seven experienced operators and importers who have at one time or the other worked with Risk Management and Scanning Service Organization and/or used the Cargo scanners especially at the airports and seaports in Nigeria. The breakdown of the population is presented in Table 1.

Table 1. Breakdown of Sample Population

\begin{tabular}{|l|l|l|}
\hline S/No. & Category of respondent & Number \\
\hline 1. & Scanner Manager & 2 \\
\hline 2. & Maintenance Engineer & 5 \\
\hline 3. & Image Analysts & 10 \\
\hline 4 & Data Capture specialist & 15 \\
\hline 5. & Image Auditor & 5 \\
\hline 6. & Scanner operators & 10 \\
\hline 7. & Importers & 50 \\
\hline
\end{tabular}

\section{Instruments}

Semi-structured questionnaires were used as aid to buttress the data gathered from observation. Each questionnaire was divided into two main sections: a profile and a survey respectively. The profile contains socio-demographic characteristics of the respondents such as age, gender, job position, qualifications, years of experience on the job, previous experience on the scanning of consignment, etc. The questions were structured to reflect the research questions listed under Section I, using the Likert scale with four choices provided for each question. The choices represented the degree of agreement each respondent has against a given question. The scale in Table 2 was used to interpret the responses of all the respondents against every question.

Table 2. Likert Scale

\begin{tabular}{|l|l|}
\hline Range & Interpretation \\
\hline $3.00-3.99$ & Agree \\
\hline $2.00-2.99$ & Disagree \\
\hline $1.00-1.99$ & No opinion \\
\hline
\end{tabular}

\section{Ethical Considerations}

As this study required the participation of human respondents, particularly those persons involved in operating facilities at the ports, certain ethical issues were addressed for the purpose of ensuring privacy and safety of the participants. Among the significant ethical issues are consent and confidentiality. In order to secure the consent of the selected participants, the vital details of the study were relayed to the participants including the objectives. By explaining the details, the respondents understood the importance of their roles in the survey.

The respondents were at liberty to participate or withdraw from the demands of the investigators. Confidentiality of the participants was also ensured by not disclosing their names or personal information in the study. Only relevant details that helped in answering the questions were included.

\section{RESUlt AND DisCUSSION}

\section{A. Analysis of the Existing System}

The Cargo Scanning process involves the use of high capacity X-ray Scanners for non-intrusive inspection of shipments usually containerized or carried by trucks and discharged at the ports or border posts. The Destination Inspection programme in Nigeria provides that consignments at port of discharge (Airports, Sea ports and land border posts) may be pre-scanned and/or subjected to the cargo scanning process when routed to the red lane during the course of valuation, classification, and risk analysis on the computerized risk management system.

The Scanning process 
The cargo scanning is employed to disclose some hidden elements of high risks like guns and ammunitions, chemical products, contraband goods, etc. Some shipments which are considered dangerous for physical examination are also subjected to x-ray scanning. An added advantage is that undeclared shipments may be revealed during the scanning process thus prompting for disciplinary action and drawing up of a debit note which implies additional duty and taxes on the part of the importer. Prior to the scanning, the containers (in case of containerized goods) and non containerized goods(goods shipped via air freight) are brought to the scanning sites by the importer and/or clearing agents where the officers of the Nigeria Customs Services and/or their appointees carry out the scanning operation. Scanner-acquired images are stored on the terminal storage housed in the scanner terminal compartment. The scanner terminal is akin to a computer workstation with an embedded CPU and storage. The image analysts work on captured images using specialized software to identify areas of inconsistencies in the shipment. The scanning is conducted by skilled scanner officers.

Image analysis phase
The image analysis phase requires other documents like form $M$, risk certificate/report, single goods declaration (SGD) document, packing list, bill of lading( for sea freight), airway bill(for air freight), road way bill(for goods shipped by road), etc.

\section{B. Organizational structure in a Scanning Operations Environment}

The organogram in figure 1 shows the operational structure in a Cargo scanning operations environment.

\section{Stakeholders in the System}

The stakeholders in the system are represented in figure 2. The repository server is the collation point which may be implemented through an integrated electronic document management system since it provides a single point through which vital information associated with the trade facilitation process may be shared with other stakeholders.

\section{Process Model of the Existing System}

The procedures undertaken during the process of scanning is interplay of information flow involving different levels of operational staff. The operational flow is represented in figure 3 .

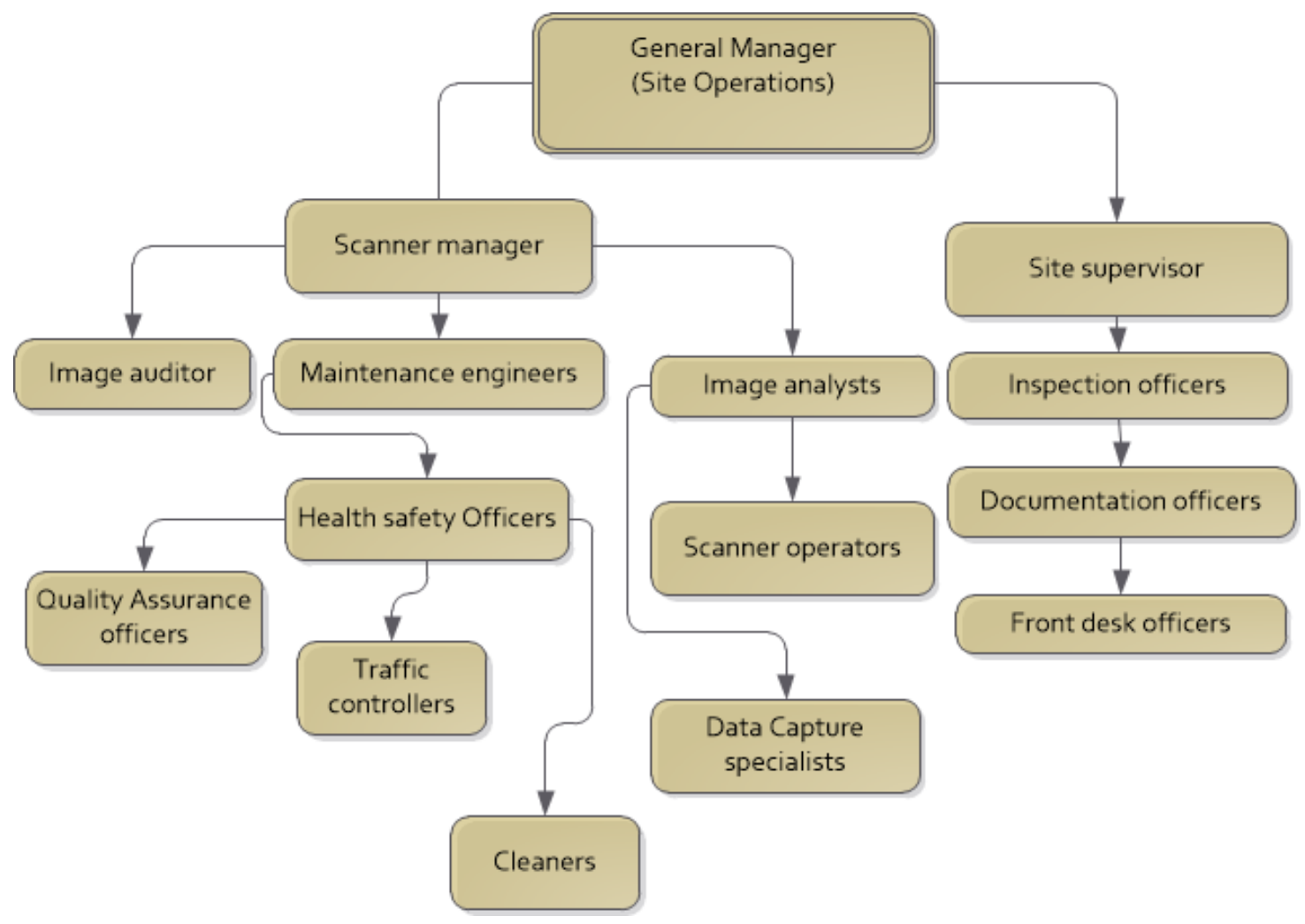

Fig.1. Responsibility structure in a Cargo Scanning Environment 


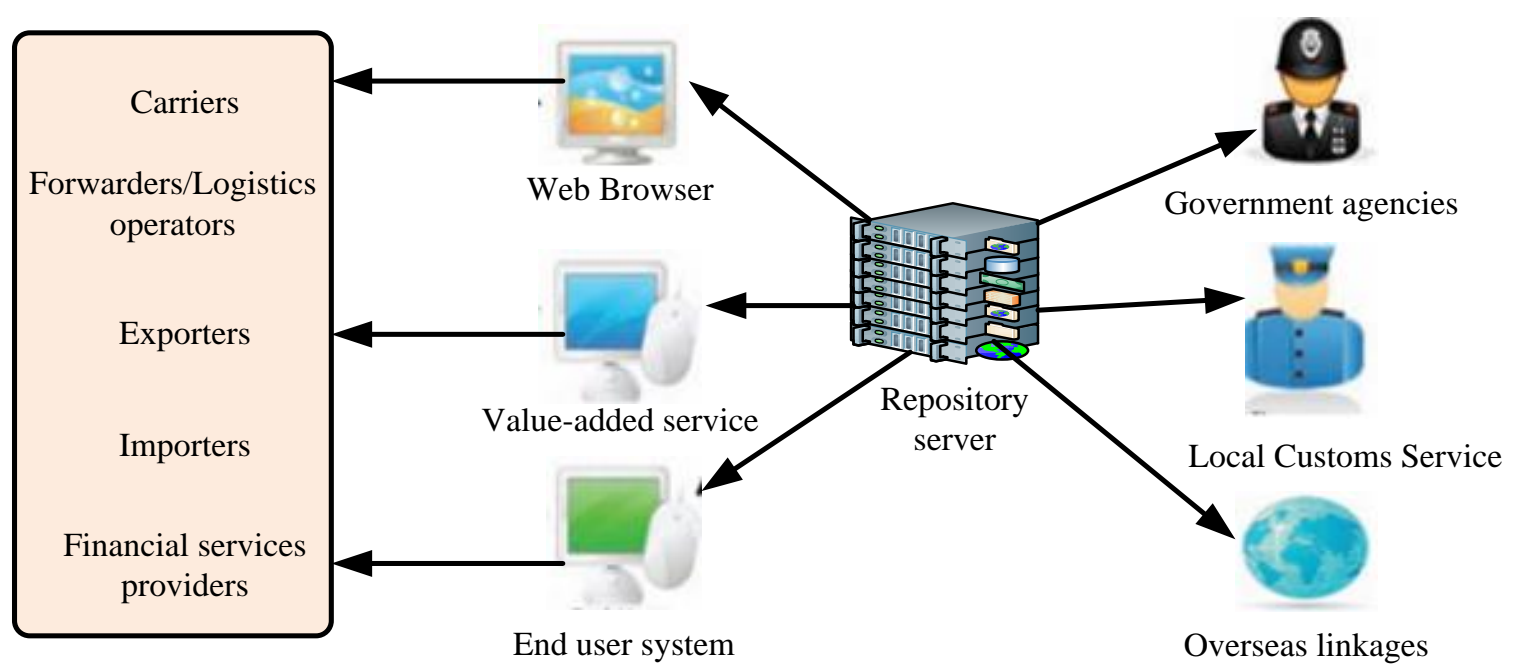

Fig.2. Stakeholders in the Trade facilitation chain

\section{E. Gaps in the system}

The following gaps were identified in the existing infrastructure:

i. Absence of a centralized or distributed repository where scanning transaction files are stored.

ii. Transaction files are mostly stored in DVDs

iii. Each scanning site maintains its data and files and this affects cumulative statistical analysis thus preventing management from making informed decisions.

iv. Optical media used at the sites often get corrupted or misplaced.

v. Movement of DVDs to image analysis location is time-consuming and challenging

\section{F. Analysis of Respondents' opinions}

The opinions gathered by the respondents as to the existing infrastructure vis-à-vis workflow performance and prospects for improvement are presented in Table 3 and figure 4 respectively.

\section{G. High Level Model of the Proposed System}

In the light of the gaps identified, a new system is proposed. The new system is a network-ready web-enabled electronic document management system with a relational database. It would have a user-friendly interface on networked workstations allowing for easy access(via a web browser) to documents, electronic archival from all scanning locations, storage of huge volumes of data, images, articles, etc. communication is made easier via network workstations at strategic locations. When a document is needed, a user with appropriate privileges searches for the document on a central repository via a relational database which makes retrieval much easier.

The cost of maintaining endless file cabinets and CD/DVD packs is done away with since a much reliable data storage area network exist. A high level model of this system is shown in figure 5 .

Table 3. Respondents' opinions

\begin{tabular}{|c|l|l|l|l|}
\hline Question & Content & Disagree & Agree & No opinion \\
\hline $\mathbf{1 .}$ & $\begin{array}{l}\text { Organization of workflow improves efficiency of cargo clearance } \\
\text { operations }\end{array}$ & 4 & 80 & 13 \\
\hline $\mathbf{2}$ & Cargo Scanning service workflow exists & 70 & 20 & 7 \\
\hline $\mathbf{3}$ & Existing Documentation workflow is fraught with problems & 4 & 93 & 0 \\
\hline $\mathbf{4}$ & Workflow is not real-time & 3 & 92 & 2 \\
\hline $\mathbf{5}$ & Workflow documentation is currently done through an EDMS & 94 & 0 & 3 \\
\hline $\mathbf{6}$ & $\begin{array}{l}\text { Image analysis and prompt reporting tasks are improved by timely } \\
\text { access to cargo scanning documentation }\end{array}$ & 3 & 79 & 15 \\
\hline $\mathbf{7}$ & EDMS can resolve all documentation problems & 1 & 77 & 19 \\
\hline $\mathbf{8}$ & $\begin{array}{l}\text { You are deeply concerned about the challenges in the current } \\
\text { system }\end{array}$ & 25 & 69 & 3 \\
\hline $\mathbf{9}$ & Funding is the main limitation to the adoption of an EDMS & 1 & 94 & 2 \\
\hline $\mathbf{1 0}$ & $\begin{array}{l}\text { Management are opposed to the use of a sophisticated technology } \\
\text { like EDMS }\end{array}$ & 49 & 43 & 5 \\
\hline
\end{tabular}




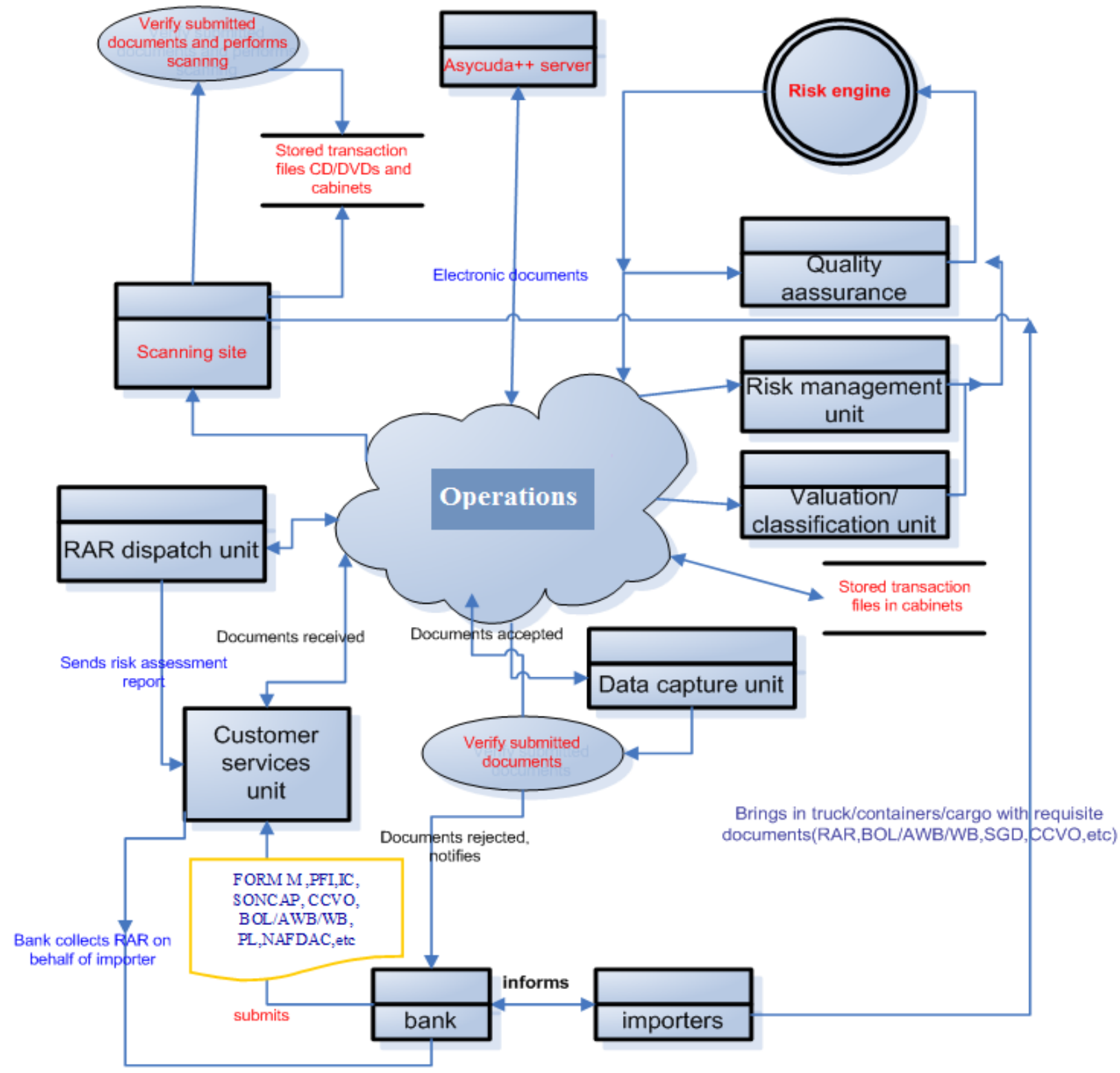

Fig.3. Process Model of the system 


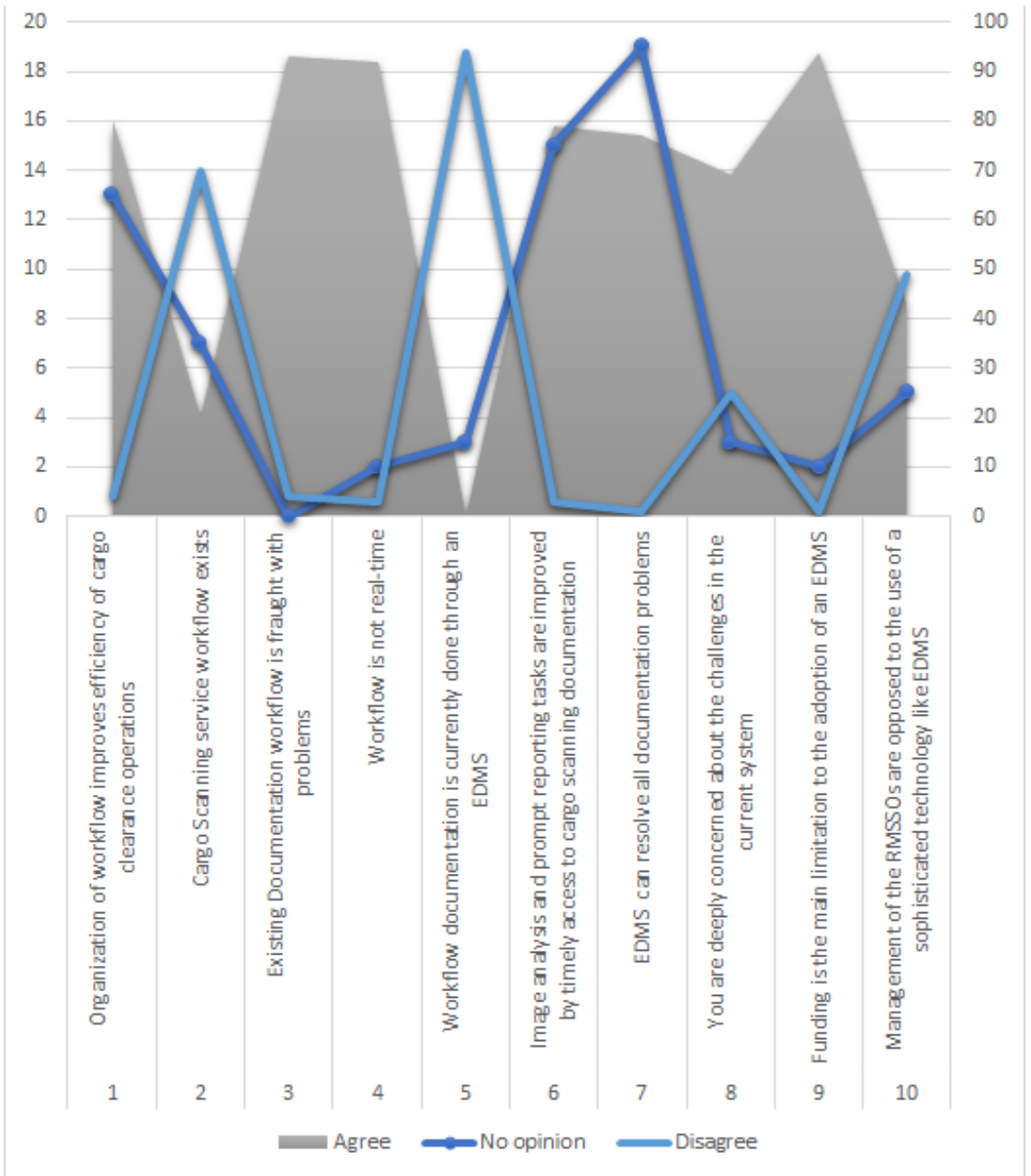

Fig.4. Stacked area charts showing Experts' views on relevance of EDMS for operations

\section{H. Design}

The objectives of the design are:

$\checkmark \quad$ To determine the nature of inputs and outputs in the proposed system

$\checkmark$ To specify the data items required in order to produce the required outputs

$\checkmark$ Decide the medium and format of all input and output taking into account hardware and software requirements.

$\checkmark$ Define in details the procedures to be employed during the data capture stage.

$\checkmark$ Produce data architecture and control specifications.

\section{The Control centre}

The system is a web-based application that provides room for other information elements which are not part of the EDMS. It provides for flexibility to cater for future system expansion. However the EDMS is designed to have an authentication layer that ensures access is only granted to users with access credentials. On successful authentication, the user control window is invoked. This control window provides several options to the user in the form of menus, buttons and hyperlinks.

\section{Data Modelling of the New System}

The data models of the proposed system are expressed at three levels: conceptual, logical, and physical. The essence of adopting this design is to thoroughly identify and examine relationships at different development levels so as to ensure accurate representation of data requirements of the system. The conceptual data model is shown in figure 6 . 


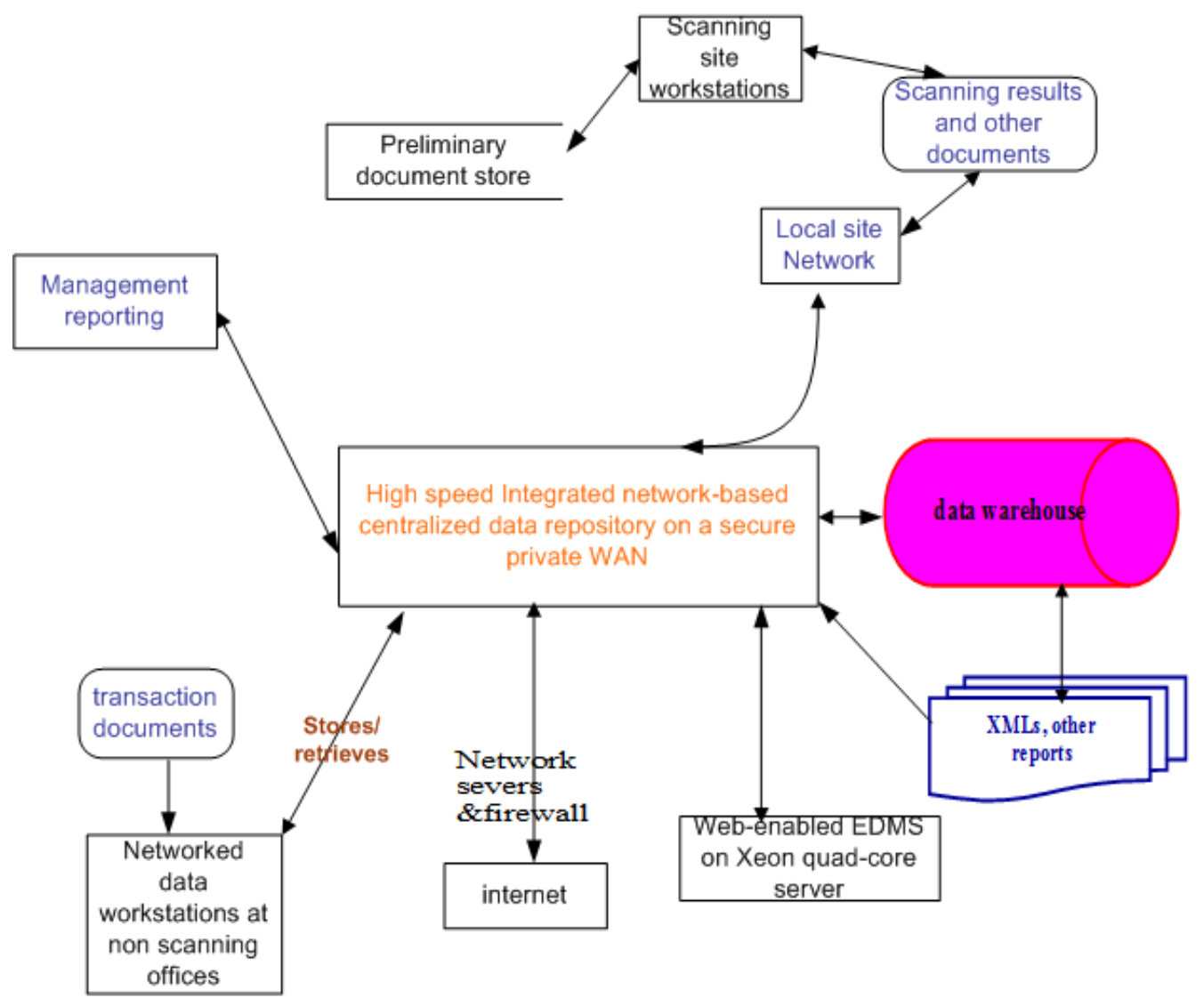

Fig. 5: Physical Model of the Proposed System

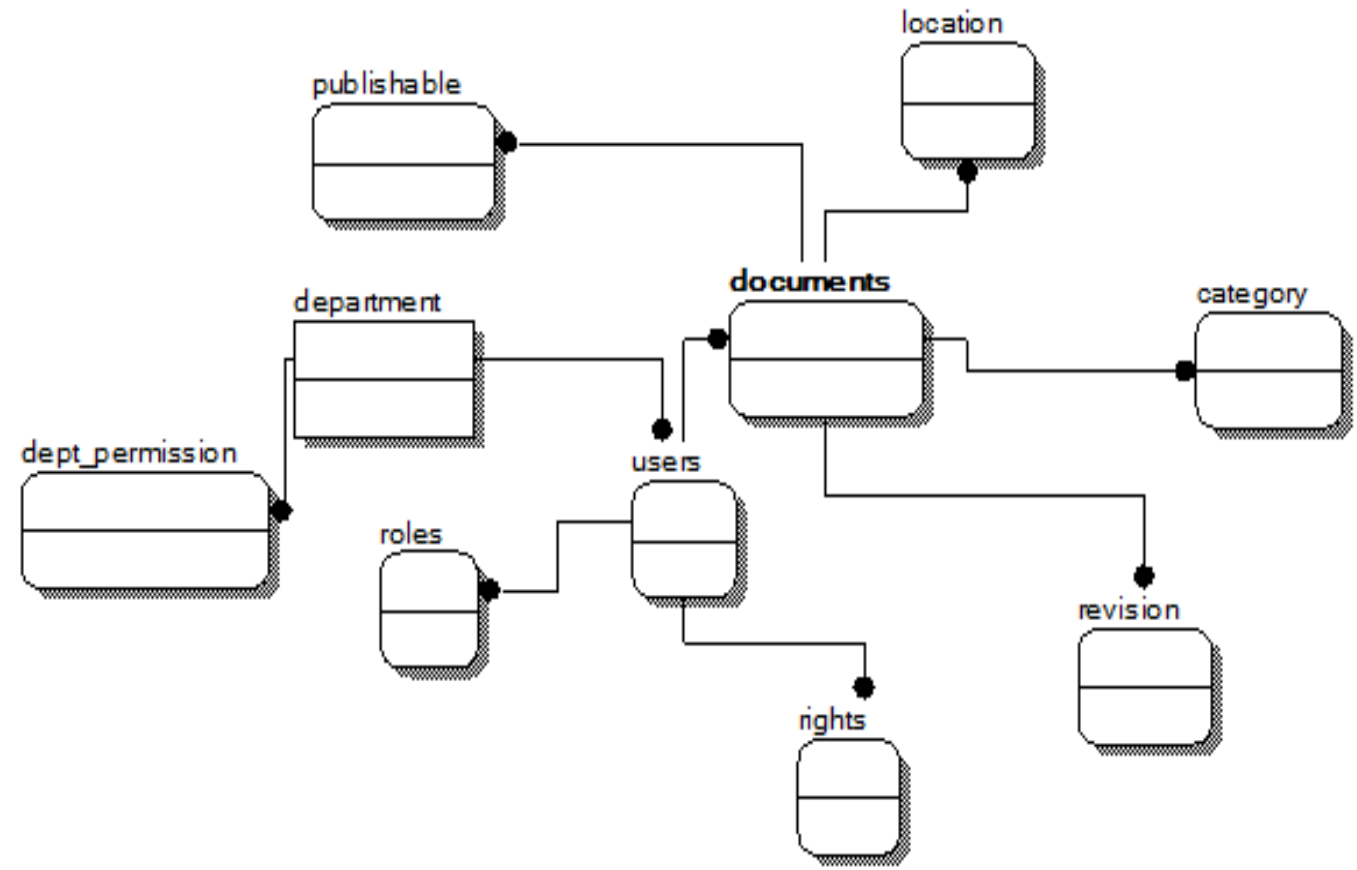

Fig.6. Conceptual Data Model of the System 
The logical data model is shown in figure 7 below.

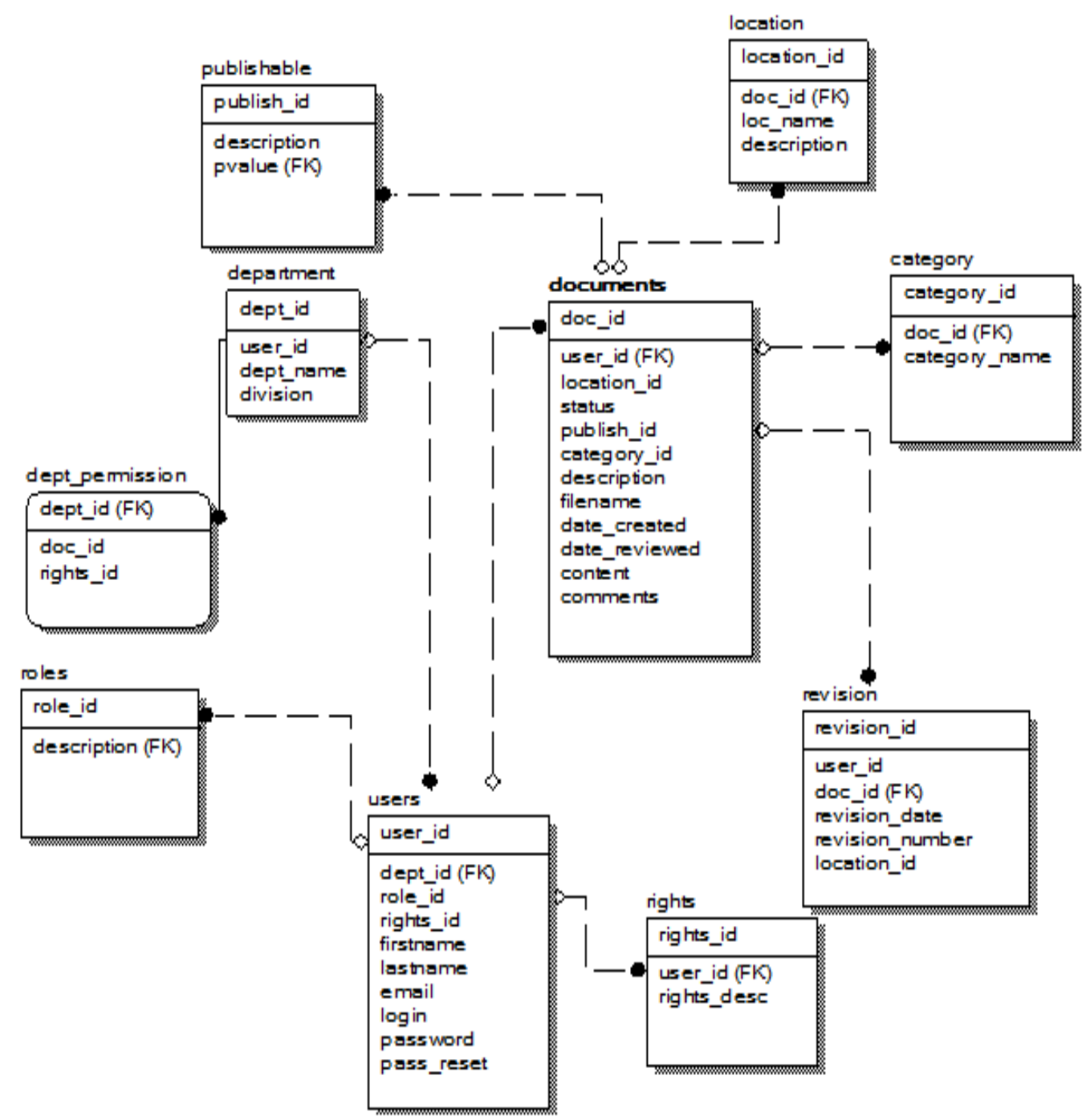

Fig.7. Logical Data Model of the EDMS

The physical data model is shown in figure 8 . The physical database design is based on MySQL Cluster 7.1.10, a full real-time and open-source transaction/database server. This Database offers a much easier integration with the web programming platform (PHP) and Apache server, another open-source and highly efficient Web server. 


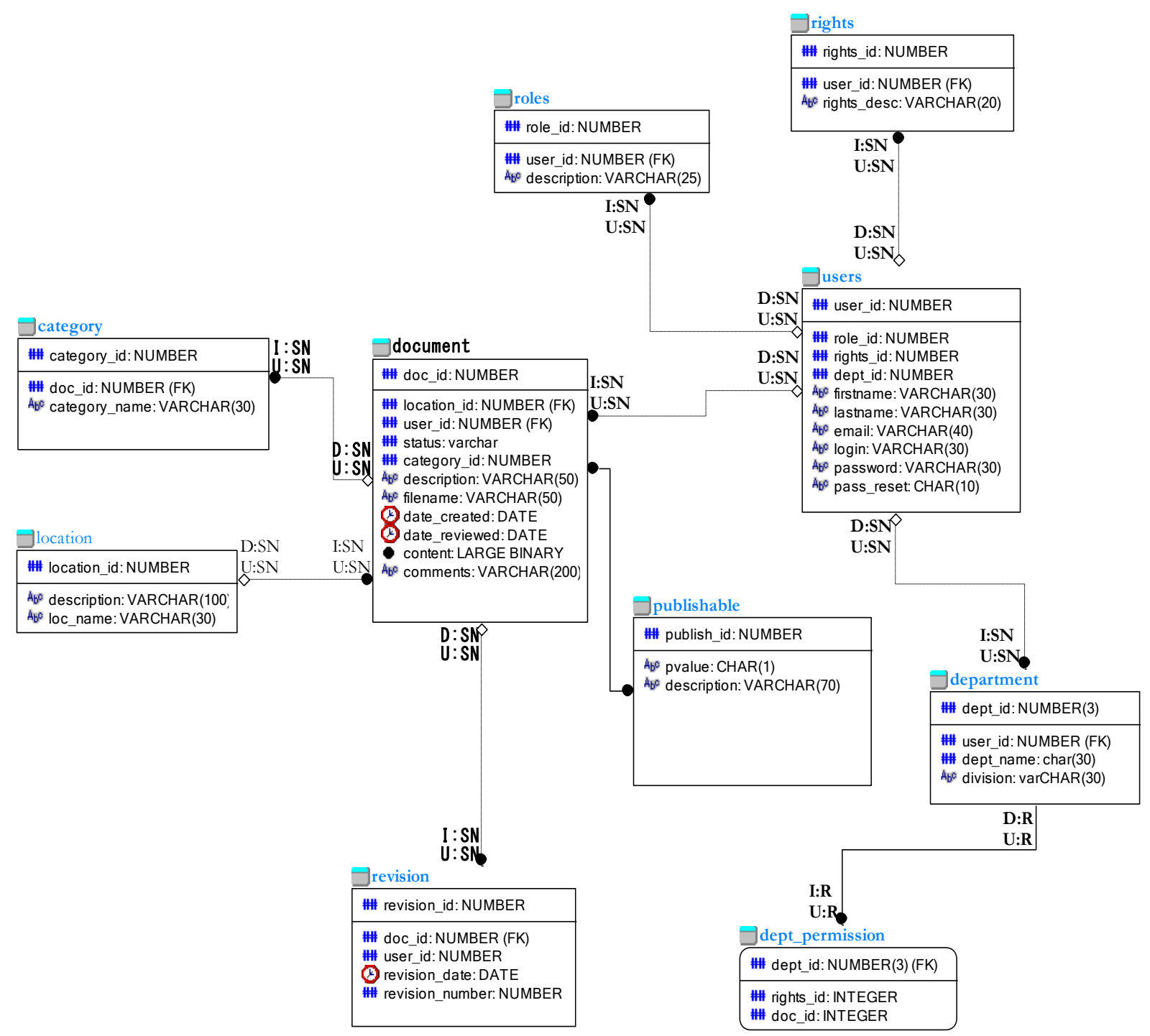

Fig.8. Physical Data Model of the system

\section{CONCLUSION}

This part of the study examined the risk management procedures particularly the aspects involving cargo scanning in a bid to identify gaps that may be remedied through an EDMS solution. Data were gathered through: questionnaire, and realtime observation of events at the scanning sites. Based on the analysis following data collection, the following conclusions are made:

i. Cargo scanning operations at the ports are sub-optimally conducted.

ii. The documentation associated with cargo scanning is not efficiently done owing to infrastructural gaps

iii. Image analysis and profiling are key to decision making hence should be improved.

iv. Transmission of scanner-acquired images of shipments to remote locations for subsequent analysis has remained a challenge to the operators and had negative impact on risk profiling and decision making.

v. An integrated electronic document management system is a prospective solution to eliminating the bottlenecks limiting effective service delivery along the trade facilitation chain.

\section{RECOMMENDATION}

Following the findings in this paper, it is recommended that the implementation of an integrated electronic document management solution that caters for document collation, archival, security, processing, and retrieval needs of all the stakholders in the trade facilitation chain is a cost-effective national investment on infrastructural reforms to boost efficiency, revenue generation and national security. 


\section{REFERENCES}

[1] W. Nwankwo, B.S. Olanrewaju., \& T. C. Olayinka, "Document Interchange Framework for Tertiary Institutions", World Journal of Engineering Research and Technology, Vol. 3, Issue 5, pp.144-162, 2017

[2] W. Nwankwo, B. S. Olanrewaju, \& T. C. Olayinka, "Document Interchange Modeling with the Zachman Framework: Nigeria's Institutions in Perspective. World Journal of Engineering Research and Technology, Vol.4, Issue 2, pp.52-63, 2018.

[3] T. Callinan, "How AI, Machine Learning \& Automation Will Impact Business In 2018 and Beyond", April 2018. https://magazine.startus.cc/ai-machine-learning-automatio n-will-impact-business-2018-beyond/ [Accessed 20 March 2019]

[4] J. Manyika et al., "A Future That Works: Automation, Employment, and Productivity", McKinsey Global Institute, January 2017. https://www.mckinsey.com/ /media/mckinsey/featured\% 20insights/digital\%20disruption/harnessing\%20automatio n\%20for\%20a\%20future $\% 20$ that $\% 20$ works/a-future-thatworks-executive-summary-mgi-january-2017.ashx [Accessed 2 April 2019]

[5] Spade Technology, "The Age of Automation and How it Impacts Business and Workflow", 2019. https://www.spadetechnology.com/the-age-of-automationand-how-it-impacts-business-and-workflow/ [Accessed 12 March 2019]

[6] Mighty Guides, "The Impact of Automation on Modern Business", Mighty Guides, Inc. New York: Great Neck, 2019.

https://www.ca.com/content/dam/ca/us/files/ebook/the-im pact-of-automation-on-modern-business.pdf [Accessed 23 February 2019]

[7] F. Garrard, "How oil and gas firms can increase competitive advantage with technology", 10 September 2019.

https://www.airswift.com/blog/automation-benefits-oil-ga s/ [Accessed 24 March 2019]

[8] N. Ismail, "Tech as a competitive advantage in logistics", $10 \quad$ January 2018. https://www.information-age.com/technology-advantage-1 ogistics-123470298/ [Accessed 19 November 2018]

[9] Business Intelligence, "Supply chain companies seek competitive advantage with automation", 8 April 2016. https://www.businessinsider.com/supply-chain-companies -seek-competitive-advantage-with-automation-2016-4?IR $=\mathrm{T}$ [Accessed 2 November 2018]

[10] World Economic Forum, "The Future of Jobs Report 2018, Centre for the New Economy and Society", 2018. http://www3.weforum.org/docs/WEF_Future_of_Jobs_20 18.pdf [Accessed 20 January 2019]

[11] A. Bridgwater, "Without workplace automation UK businesses will fail, Technology/Robotics \& Automation", $28 \quad$ June 2017. https://www.raconteur.net/technology/without-workplaceautomation-uk-businesses-will-fail [Accessed 15 March 2019]

[12] T. Tobin, "What to consider as the Automation Economy Transforms Business Today", Nice Limited, 2017. https://www.nice.com/websites/rpa/assets/Automation-Ec onomy-by-TomTobin.pdf [Accessed 15 March 2019]

[13] HTDS, "Cargo x-ray Scanner", 2019. https://www.htds.fr/en/security/x-ray-scanner/cargo-X-rayscanner/ [Accessed 6 May 2018]
[14] World Customs Organization, "Guidelines for the Procurement and Deployment of Scanning Equipment", Brussels, 2016.

[15] Smiths Detection, "Heavy Cargo \& Vehicle Inspection", 2019.

https://www.smithsdetection.com/prodcat/heavy-cargo-ve hicle-inspection/ [Accessed 12 March 2018]

[16] Smiths Detection, "HI-SCAN 180180-2is pro: Advanced dual view X-ray cargo scanner", 2019. https://www.smithsdetection.com/products/hi-scan-18018 0-2is-pro-2/ [Accessed 12 March 2018]

[17] W. Nwankwo, "Customs Automation: The X-ray and Computerized Risk Management Systems Era" International Journal of Science and Research, Vol. 6, Issue 4, pp. 735-741, 2017

[18] D. Bychkov,"What are the Best Document Management Systems?”, Segui Technologies, 25 February 2013. https://www.seguetech.com/best-document-management-s ystems/ [Accessed 15 March 2019]

[19] A. Alina, J. Küng, G.S. Czibulla, \& C. Sacarea, "Designing a General Architecture for Data Interchange", International Conference on Web Information Systems and Technologies (WEBIST), 2014

[20] I.N. Burtylev, K.V. Mokhun, Y.V. Bodnya \& D.N. Yukhnevich, "Development of Electronic Document Management Systems: Advantage and Efficiency", Science and Technology, Special Issue, pp. 1-9, 2013.

[21] A. Mahmood \& I.T. Okumus, "Design and Implementation of an Electronic Document Management System", MAKÜ-Uyg. Bil. Derg., Vol. 1, Issue 1, pp.9-17, 2017

[22] M. Maaranen, "An Implementation Process for a revised Document Management System", Masters Thesis, Helsinki Metropolia University of Applied Sciences, 2017.

[23] J. Obee, "Choosing and Implementing an Electronic Document Management System", Barnet London Borough, $29 \quad$ April 2017. https://cdn.ymaws.com/irms.org.uk/resource/collection/C4 40C319-CE10-44AF-A0DF-BC06F876F5B2/20170428_I mplementing_a_Electronic_Document_Management_Syst em_v2.0.pdf [Accessed 05 April 2019]

[24] A. Carzaniga \& A.L. Wolf, "Content-based Networking: A New Communication Infrastructure", SF Workshop on an Infrastructure for Mobile and Wireless Systems. In conjunction with the International Conference on Computer Communications and Networks, Scottsdale, AZ, 2001.

[25] M.R. Haas \& M.T. Hansen, "Competing for attention in knowledge markets: Electronic document dissemination in a management consulting company", Administrative Science Quarterly, Vol. 46, pp.1-28, 2001.

[26] J. Marin \& A. Poulter, "Dissemination of Competitive Intelligence", J. Information Science, Vol. 30, Issue 2, pp. 165-180, 2004.

[27] B.C. Bjoerk, P. Huovila \& S. Hult, "Integrated construction project document management," in Proceedings of the EuropIA'93 conference, M. Behesti \& K. Zreik, eds. Delft: Elsevier, pp. 135-146, 21-24 June, 1993.

[28] B.C. Bjoerk, "The RATAS project - a n example of co-operation between industry and research towards computer integrated construction", ASCE Journal of Computing in Civil Engineering, Vol. 8, No. 4, pp.401-419, 1994.

[29] Z. Turk Z., B.C. Bjoerk, K. Johansson \& K. Svensson, "Document management systems as an essential step towards CIC", CIB W78 Workshop on Computer Integrated Construction, Helsinki: VTT, 22-24 August, 1994. 
[30] P.H. Debras, Y. Rezgui, P. Le Ber, \& C. Chaplais, "Projet DOCCIME: Système logiciel pour l'intégration de l'ingénierie documentaire dans le processus de conception - Rapport final", Internal Report, Sophia-Antipolis: CSTB, 1994.

[31] Y. Rezgui, A. Brown, G. Cooper, G. Aouad, J. Kirkham \& P. Brandon, "An integrated framework for evolving construction models", unpublished.

[32] Y. Rezgui, "Integration des systèmes d'informations techniques pour l'exploitation des ouvrages", $\mathrm{PhD}$ thesis, Paris: Ecole Nationale des Ponts et Chaussées, 1994.

[33] DMWare, "Open Document Management API (ODMA) specification", version 2.0, 1997.

[34] DMWare, "Document Management Alliance (DMA) specification 1.0-7", 2202.

[35] ISO,"ISO/TC 171: Document management applications", 2019. https://www.iso.org/committee/53650/x/catalogue/ [Accessed 14 April 2019]

[36] Y. Goland, E. Whitehead, A. Faizi, S. Carter \& D. Jensen, "RFC 2518. HTTP Extensions for Distributed Authoring WEBDAV”, 1999.

\section{Authors' Profiles}

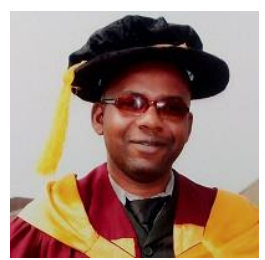

Wilson Nwankwo is an Associate Professor in Computer Science at Edo University Iyamho Nigeria, and a Consultant on Instrumentation and Control with Stewart Intersea Limited Lagos. He obtained a Ph.D in Information Technology from Federal University of Technologgy Owerri Nigeria. He is a core industry expert and prior to joining the academic career train, he spent over 16 years working on cutting edge IT projects in reputable organizations cutting across Manufacturing, Risk Management, International Trade, insurance and Banking. He is an active member of learned professional societies including: Nigeria Computer Society; Computer Professionals Registration
Council of Nigeria; Project Management Institute; Information Systems Audit \& Control Association (ISACA); Institute of Electrical \& Electronic Engineers; Institute of Software Practitioners of Nigeria to name a few. His research interests are: Intelligent Enterprise Systems; Software engineering, Artificial Intelligence; Analytics; Embedded systems, Wireless Networks, and high availability Data systems.

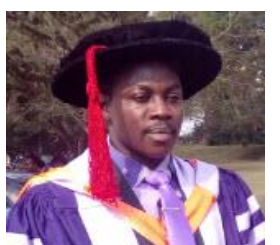

Akinola S. Olayinka is a Senior Lecturer in the Department of Physics at Edo University Iyamho, Nigeria. He holds Ph.D in Physics. His research focus is the application of modern theoretical concepts of materials based on the quantum theory of solids and powerful computational methods to realistic situations. He uses various theoretical and computational tools to address societal needs, such as the development of novel materials for efficient solar application, materials for better energy storage, materials for thermoelectric applications and biomaterials.He has over 25 publications to his credit and is an active reviewer to many Journals.

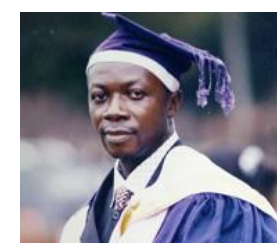

Benjamin Uchenna Benson obtained his MSc in Information Technology from the Federal University of Technology Owerri (FUTO) Nigeria. He received his BSc in Computer Science from the University of Benin, Edo State, Nigeria. Prior to his academic career, Mr. Benson has worked with several national and International Organizations in the Industry including Electricity Power Generation and Distribution, Import/Export Risk Management, and Trade facilitation companies. He is currently a Lecturer in the Department of Computer Science at Imo State Polytechnic now Imo State University of Agriculture \& Environmental Sciences, Umuagwo, Nigeria. His research interests are CyberSecurity, Cloud Computing, Embedded systems, and Internet of Things (IoT).

How to cite this paper: Wilson Nwankwo, Akinola S. Olayinka, Benjamin Uchenna Benson, "X-ray Cargo Scanning and Risk Management in Trade Facilitation: Analysis \& Model of an Online Imaging and Documentation Management System", International Journal of Modern Education and Computer Science(IJMECS), Vol.11, No.5, pp. 10-23, 2019.DOI: 10.5815/ijmecs.2019.05.02 